Forum 2019 · 34:92

https://doi.org/10.1007/s12312-018-0538-5

Online publiziert: 7. Dezember 2018

(c) Springer Medizin Verlag GmbH, ein Teil von

Springer Nature 2018

\title{
BAYERISCHE
}

KREBSGESELLSCHAFT

Die Bayerische Krebsgesellschaft e.V. (BKG) und die Prostata Hilfe Deutschland (PHD) arbeiten zukünftig in der Aufklärung über Prostatakrebs eng zusammen.

Ziel der Kooperation ist es, drängende Fragen von erkrankten Männern und deren Angehörigen leicht verständlich, seriös und möglichst umfassend zu beantworten. Damit erhalten Betroffene eine erste Orientierungshilfe, die ihnen die eigene, meist mühsame Recherche im Internet ersparen soll.

Männer sind im Vergleich zu Frauen immer noch wahre Vorsorge-Muffel: Nur etwa jeder vierte Mann im Alter ab 45 Jahren nimmt derzeit die angebotenen Früherkennungs-Untersuchungen in Anspruch. Mit gezielter Aufklärung wollen BKG und PHD die Vorsorgebereitschaft von Männern im Alter ab 45 Jahren erhöhen und damit ihre Gesundheitskompetenz verbessern. Um das zu erreichen, planen die Partner, ihre bestehenden Informationsangebote zu vernetzten und durch neue, gemeinsam entwickelte digitale Medien, Ratgeber und Veranstaltungen zu erweitern. „Durch die Zusammenarbeit werden wir die Zahl der gut informierten Krebsbetroffenen weiter erhöhen und die Öffentlichkeit stärker für die Bedeutung der ambulanten psychosozialen Krebsberatung sensibilisieren“, betont Professor Günter Schlimok, Präsident der BKG. Dr. Knut Müller, Vorsitzender der PHD, freut sich darüber, künftig auf die langjährige Erfahrung der BKG zurückgreifen zu können, um die PHD weiterzuentwickeln. Müller: „Das ist für unsere Organisation und somit für alle Prostata-Erkrankten ein großer qualitativer Gewinn.“

Bayerische Krebsgesellschaft e.V.

München, Deutschland

\section{Bayerische Krebsgesellschaft und Prostata Hilfe Deutschland informieren gemeinsam über Prostatakrebs}

\section{Aufklärung fürr Männer ab 45}

Auf der Internetseite: www.prostatahilfe-deutschland.de finden Erkrankte alle wichtigen Informationen zur Behandlung von Prostatakrebs. Dafür entwickelt die PHD eigens Video-Clip-Gespräche mit Experten und Betroffenen und informiert in einem Newsfeed über aktuelle Entwicklungen in der Therapie. Durch die Verlinkung auf die Webseite: www.bayerische-krebsgesellschaft.de der BKG haben Betroffene schnellen Zugriff auf psychosoziale Informationen und das Angebot der BKG.

Wie wichtig ein solches lebensnahes Beratungsangebot ist, wissen die Gründer der PHD, Dr. Knut Müller und Michael Reinhard, aus eigener Erfahrung. Beide erkrankten vor einigen Jahren an Prostatakrebs. Mit der Diagnose begann für sie eine lange und ermüdende Suche nach verlässlichen Informationen: „Selbst für einen Recherche-Profi wie mich war es bei rund 1000 Seiten zum Thema Prostatakrebs fast unmöglich, eine begehbare Schneise in diesen Informationsdschun-

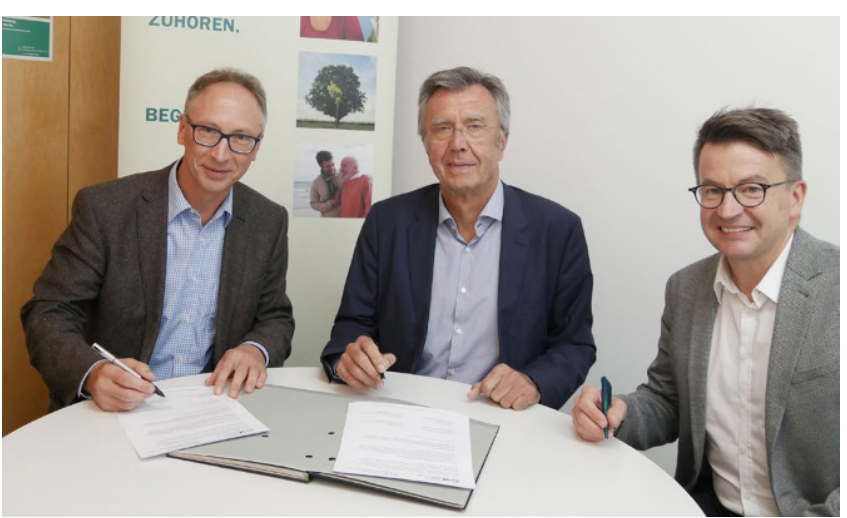

$\checkmark$ v. I.n.r.: Dr. Knut Müller (Vorsitzender PHD), Professor Günter Schlimok (Präsident BKG) und Markus Besseler (Geschäftsführer BKG) unterzeichnen den Kooperationsvertrag. (C) Bayerische Krebsgesellschaft) 